\title{
Prevalence of self-reported tuberculosis, knowledge about tuberculosis transmission and its determinants among adults in India: results from a nation-wide cross-sectional household survey
}

\author{
Chandrashekhar T Sreeramareddy ${ }^{1 *}$, H N Harsha Kumar ${ }^{2}$ and John T Arokiasamy ${ }^{3}$
}

\begin{abstract}
Background: Knowledge about symptoms and transmission of tuberculosis determines health seeking behavior and helps in prevention of tuberculosis transmission in the community. Such data is useful for policy makers to formulate information, education and communication strategies for tuberculosis control.

Methods: A secondary data analysis of India demographic and health survey, 2005/6 was carried out. Questions about self-reported tuberculosis, transmission and curability of tuberculosis were analysed. Correct knowledge (without misconceptions) about tuberculosis transmission was used as a dependant variable and the explanatory variables tested were: demographic data, education, wealth quintiles, frequency of exposure to media and the curability of tuberculosis. Determinants of correct knowledge without misconceptions were tested by univariate and multivariate analyses using national weighting factor to adjust for complex sampling design.

Results: A total of 109,070 households (response rate of 93.5\%) and 198,718 participants (response rate of 91.6\%) completed the survey. The samples of men and women interviewed were 74,360 and 124,358 respectively. Prevalence rate of self-reported tuberculosis was 445 per 100,000 usual household residents and 4.60 per 1,000 participants. The number of respondents who had "heard of an illness called tuberculosis" was 177,423 (89.3\%). Of these 47,487 (26.8\%) participants did not know and 55.5\% knew about the correct mode of tuberculosis transmission i.e. "Through the air when coughing or sneezing". The common misconceptions about transmission were "Through food" (32.4\%), "Sharing utensils" (18.2\%), and "Touching a person with tuberculosis" (12.3\%). Only 52,617 (29.7\%) participants had correct knowledge without misconceptions. Being male (aOR 1.17, 95\% Cls 1.14, 1.21), being a Hindu (aOR 1.20, 95\% Cls 1.14, 1.26) or Muslim (aOR 1.26, 95\% Cls 1.18, 1.34), listening to radio (aOR 1.08, 95\% Cls 1.04, 1.13) and "Tuberculosis can be cured" (aOR 1.47, 95\% Cls 1.41, 1.53) were associated with correct knowledge without misconceptions.
\end{abstract}

Conclusions: Knowledge about tuberculosis transmission is very poor and misconceptions still exist. Among the traditional mass media, the frequency of listening to radio was associated with correct knowledge about tuberculosis transmission. Strategies to deliver information, education and communication campaigns could be improved.

\footnotetext{
* Correspondence: chandrashekharats@yahoo.com

'Department of Clinical Sciences, Faculty of Medicine and Health Sciences, Universiti Tunku Abdul Rahman, Sungai Long, Malaysia

Full list of author information is available at the end of the article
} 


\section{Background}

Tuberculosis (TB) is a global public health problem with a third of the world's population infected with Mycobacterium tuberculosis [1]. TB accounted for 9.4 million new cases, 11.1 million prevalent cases and 1.3 million deaths during the year 2008 [2]. In low- and middle-income countries (LMICs), TB stands third among the leading causes of adult mortality after human immunodeficiency virus and ischaemic heart disease [3]. Out of the 22 highburden countries for TB, eleven are situated in Asia, while nine are in Africa. These countries account for approximately $80 \%$ of the total cases worldwide. In Asia, India is also a high-burden country along with China [2]. The average prevalence of all forms of tuberculosis and smearpositive cases was estimated at 5.05, and 2.27 per 1,000 population respectively with an annual incidence of smear-positive cases at 84 per 100,000 population [4]. In India during 2010, the estimated prevalence rate for all forms of TB was 283 per 100,000 population. In India, each year nearly 2.2 million people develop TB disease, of which one million are new smear-positive cases and half a million people die from TB [5].

Up until now, early case detection and treatment of cases is the only and most effective method of TB control [6]. The current TB control strategy with Directly Observed Treatment; Short course (DOTS) is reported to be successful in terms of treatment success rate [7]. However, passive case detection strategy followed under DOTS may not have achieved the case detection rate of at least $70 \%[8,9]$. In India, a passive case detection method is followed under the Revised National Tuberculosis Control Program (RNTCP) for TB case-finding. This may be the reason for the delayed presentation of TB patients at healthcare facilities where diagnostic facilities for TB are available [10]. Two systematic reviews on the delay in diagnosis of TB have highlighted that longer patient delays may be due to lack of awareness about TB symptoms among the population [11,12]. Therefore, TB control programs have recognized the importance of providing information, education and communication (IEC) to improve the knowledge about TB and to influence change in health-care seeking behavior among both TB patients and the general public. In India, though an integral component of RNTCP, IEC activities were minimal and scattered up until 2001. Since 2001, a sustained intensified IEC campaign is being done [7]. Recently, a STOP-TB initiative has adopted the strategy of advocacy, communication and social mobilization to support country TB control programmes [7,13,14].

Knowledge about TB symptoms, modes of transmission of $\mathrm{TB}$, and misconceptions about TB transmission among the general public may have an impact on health-care seeking behavior $[15,16]$. A sound understanding of the knowledge about symptoms and misconceptions about
TB transmission in the general population is important to formulate messages for health education. Surveys about knowledge, attitude and practice may yield data for impact assessment of the ongoing IEC campaign [16-19]. A few studies have reported about the knowledge of TB transmission in the general population, medical interns and physicians [15,20-23]. A study about knowledge of TB transmission among ever-married women in Bangladesh has been reported [24]. However, there are no reports on a nationally representative sample from India. We analyzed such information available in the data from India Demographic Health Survey 2005/6. Our objectives were to provide prevalence estimates of self-reported TB, to assess the knowledge and misconceptions about TB transmission and to identify the determinants of 'correct knowledge' about TB transmission.

\section{Methods}

\section{Data source}

India Demographic and Health Survey, 2005/6 (IDHS 2005/6) which is also called as the National Family and Health Survey-III (NFHS-III) was conducted between November 2005 and August 2006 under the scientific and administrative supervision of the International Institute for Population Sciences (IPPS), Mumbai and ORC (Opinion Research Corp.) Macro International. Trained interviewers collected data on demographic factors, socio-economic factors and health status from a nationally representative probability sample of households. Data were collected according to a standard protocol of Demographic and Health Survey (DHS) which had three core survey questionnaires i.e. the Household Questionnaire, the Woman's Questionnaire and the Man's Questionnaire. The questionnaires were translated into 18 local languages; field tested and were subsequently back-translated to English. These questionnaires were used in all 29 states of India. In each of these states, the questionnaires used were bilingual i.e. questions were in the principal language of the state, and in English. To minimize language barriers, the survey was administered by trained interviewers either in English or in the principal language of the state or the preferred language of the household.

\section{Sampling methods}

A nationally representative sample of households was selected through a stratified, multistage cluster sampling method. By this method, the households were selected by the two-stage probability proportional to size (PPS) method in rural areas and the three stage PPS sampling method in urban areas (Figure 1). A uniform sampling design was used across all the 29 states. Urban and rural samples were drawn separately and were proportionate to the population size of the state, unless oversampling was required for an area or a group. For both urban and 


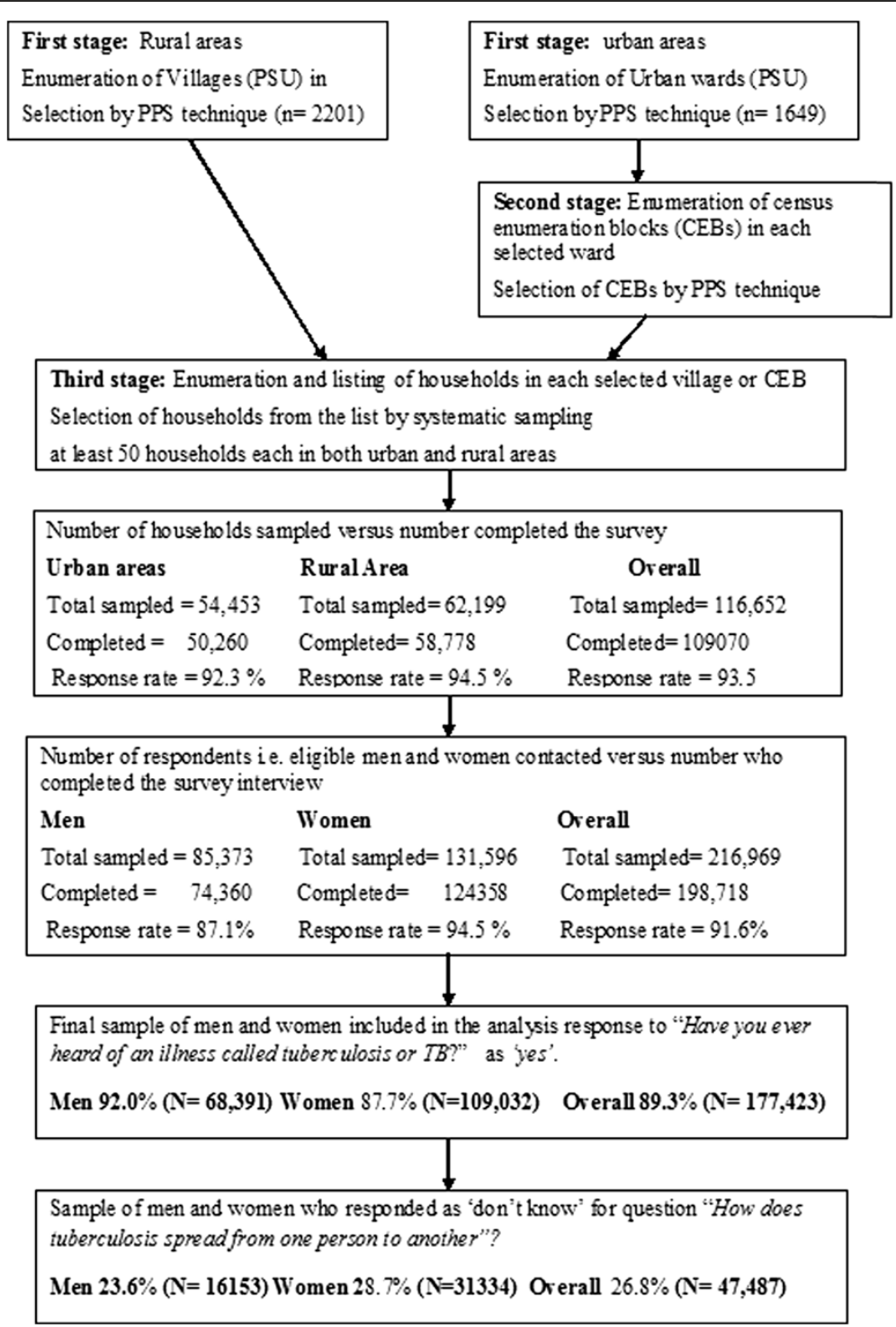

Figure 1 Sampling method and selection of sample for analysis.

rural areas, geographic sampling units obtained were villages in rural areas and census blocks/wards in urban areas. A random household sampling method with household as primary sampling unit (PSU) was undertaken in chosen geographic sampling units. Further details of sampling design and sample size obtained for this analysis are given in Figure 1. Details about training of the survey team, survey management and quality control measures are separately documented in the country reports published by ORC Macro International [25].

\section{Ethical issues and consent}

Independent review boards (IRBs) of IPPS and ORC Macro International reviewed the DHS standard protocols, data collection tools, procedures, and provided the ethical approval. Trained interviewers informed the survey participants that participation in the survey was voluntary. They were also assured about confidentiality of the information to be provided and could opt not to answer any of the questions during the interview. Informed consent was obtained from each survey participant.

\section{Variables}

In the Household Questionnaire section, the main respondent of the household was asked to list all the usual residents living the house. The main respondent was asked "Do any usual resident of your household suffer from tuberculosis?” If the response was 'yes', they were 
then asked "Who suffers from tuberculosis?" Responses to these questions were used to estimate the prevalence of self-reported TB. Both men and women were asked two main questions about TB in their respective questionnaires. The first one was "Have you ever heard of an illness called tuberculosis or TB?" If the response to the first question was 'yes', then a second question "How does tuberculosis spread from one person to another?" was asked to assess their knowledge about TB transmission. For the second question, the respondents were given following options. The responses were marked as 'yes' or 'no'.

a)Through the air when coughing or sneezing

b)Through spit/sputum/stepping on spit

c) Through sharing utensils

d)Through sharing clothes/bed sheets/towel

e)Through smoking bidis/cigarette/tobacco

f) Through touching a person with tuberculosis

g)Through food

h)Through sexual contact

i) Through mosquito bites

j) Don't know

For our analysis, the response to option a) "Through air when coughing or sneezing" was considered as correct knowledge about TB transmission. The options from ' $b$ ' to 'i' were considered as misconceptions. We created a new variable by re-coding responses to question about TB transmission. This provided us a sample of individuals who responded as 'yes' to the option 'Through air when coughing or sneezing" and responded as 'no' to other options about modes transmission for TB. The recoding gave us a new variable "correct knowledge without misconception". The other questions asked about TB were "Can tuberculosis be cured?" and "If a member of your family got tuberculosis, would you want it to remain a secret or not?"

\section{Dependant variable}

Based on the responses to questions explained above regarding $\mathrm{TB}$ transmission, a binary dependant variable 'correct knowledge about TB transmission' was created for multivariable analysis. 'Correct knowledge about TB transmission' was defined as follows: If a participant had correct knowledge (i.e. TB transmission "Through the air when coughing or sneezing") but had no misconceptions about TB transmission. Incorrect knowledge was considered either if the respondent had misconceptions despite responding as 'yes' for TB transmission 'Through the air when coughing or sneezing", or had only misconceptions or responded as "Don't know".

\section{Explanatory variables}

We tested the association between correct knowledge about TB transmission and the following explanatory variables: age, gender, highest level of education attained, marital status, religion, type of residence (urban/rural), wealth index, national region of residence and exposure to mass media (frequency of reading newspaper/magazine, listening to radio, and watching television). Wealth index is a relative index of household wealth. It was calculated based on a standard set of household assets, dwelling characteristics and ownership of consumer items according to observation by the interviewer. The individuals were ranked on the basis of their household score and divided into quintiles. The first quintile is the poorest $20 \%$ of the households and fifth quintile is the wealthiest $20 \%$ of the households. In India DHS 2006, the respondents were asked about the frequency of reading newspaper/magazine, listening to radio, and watching television. The response options were 'not at all', 'less than once a week', 'at least once a week and 'almost every day'. We also tested "Can tuberculosis be cured?" for association with correct knowledge about TB transmission. For national region of residence, the 29 states were grouped as East, West, Central, North, South and North-East. National regions of residence were categorized based on those created by the International Institute for Population Sciences. These categories are as follows: North (New Delhi, Haryana, Himachal Pradesh, Jammu/Kashmir, Punjab, Rajasthan, Uttaranchal), Central (Madhya Pradesh, Uttar Pradesh, Chhattisgarh), East (Bihar, Orissa, West Bengal, Jharkhand), North-East (Arunachal Pradesh, Assam, Manipur, Meghalaya, Mizoram, Nagaland, Sikkim, Tripura), West (Goa, Gujarat, Maharashtra), South (Andhra Pradesh, Karnataka, Kerala, Tamil Nadu).

\section{Data analysis}

Response rates for households contacted and individuals invited to participate in the survey were calculated. Prevalence rates of tuberculosis per 100,000 usual residents in the household and per 1,000 respondents were calculated. For comparison of prevalence rates among the respondents by selected demographic variables, Chi-square test was used to test the statistical significance. The percentage of participants responding as 'yes' for questions about TB and its modes of transmission were calculated. The dichotomous variable 'correct knowledge about TB transmission' was used as a dependant variable for multivariable analysis to identify the determinants of 'correct knowledge about TB transmission'. The explanatory variables used were demographic factors (age, gender, religion and marital status), socio-economic factors (educational attainment and wealth quintiles), spatial factors (urban/rural residence, region/state) and other factors ("Can TB can be cured?"), frequency of reading newspaper, watching television and listening to radio). National weighting factor was used to adjust for multistage sampling used in DHS. Complex samples analysis option was used in statistical package for Social Sciences (SPSS) version 17. Univariate analyses 
followed by multivariable analyses were carried out. In multivariate analyses adjusted odd ratios (aOR) and their 95\% confidence intervals (95\% CIs) were calculated. For all these analyses a p-value $<0.05$ was considered as significant.

\section{Results}

\section{Household and participants response rates}

Of the 116,652 households that were sampled, 109,070 completed the survey giving an overall household response rate of $93.5 \%$. The response rates in urban and rural areas were $92.3 \%$ and $94.5 \%$ respectively. A total 216,969 individuals were contacted of which 198,718 responded giving an overall response rate of $91.6 \%$. The participant response rate of $94.5 \%$ for women was higher than $87.1 \%$ for men (Figure 1).

\section{Prevalence of self-reported tuberculosis}

The overall prevalence rate for tuberculosis was 445 per 100,000 usual household residents. The prevalence rate in rural areas (502 per 100,000 usual household residents) was significantly higher than the urban areas (319 per 100,000 usual household residents). Among the total of 198,754 participants, 915 reported to be suffering from tuberculosis giving an overall prevalence rate of 4.60 per 1,000 participants. The prevalence of self-reported TB according to important explanatory variables is shown in Table 1. The prevalence was higher among those aged 40 years and above, men, poorer and poorest (by wealth quintiles), and those who did not have any education. Among the regions of India, North-Eastern and Eastern regions had higher prevalence than the rest of India. All these comparisons were statistically significant (Table-1).

\section{Knowledge about TB transmission}

Overall, a high proportion $(89.3 \%$ i.e.177, 423) of the respondents had "heard of an illness called Tuberculosis (TB)". The proportion of men (92\% i.e. 68,391) who had "heard of an illness called Tuberculosis (TB)" was higher than that of women $(87.7 \%$ i.e. 109,032). Among those who had heard about TB, $26.8 \%(47,487)$ responded as "Don't know" for the question about transmission of TB (men $23.6 \%$ versus women $28.7 \%$ ). Only $55.5 \%$ of them knew about the correct mode for transmission of TB i.e. 'Through the air when coughing or sneezing'. Various misconceptions about TB transmission prevailed among the participants. Among these, TB transmission through food (32.4\%), sharing utensils (18.2\%), touching a person with TB (12.3\%) were very common. Other misconceptions according to sex are shown in Table 2. By our operational definition only $29.7 \%$ (i.e. 52,617 ) of the participants had correct knowledge about TB transmission. The majority (83.5\%) of participants knew that TB can be cured but
Table 1 Prevalence of self-reported Tuberculosis among adult men (aged 15-59 years) and women (aged 15-49 years) by selected demographic and socioeconomic characteristics

\begin{tabular}{|c|c|c|c|c|}
\hline & $\begin{array}{l}\text { Sample } \\
\text { (N) }\end{array}$ & $\begin{array}{l}\text { Number } \\
\text { reporting TB }\end{array}$ & $\begin{array}{l}\text { Prevalence } \\
\text { per } 1000 \\
\text { population }\end{array}$ & $\begin{array}{l}95 \% \\
\text { Cls }\end{array}$ \\
\hline \multicolumn{5}{|l|}{ Age } \\
\hline$\leq 25$ years & 72300 & 187 & 2.58 & $2.22,2.96$ \\
\hline $26-40$ years & 84639 & 423 & 4.99 & $4.52,5.47$ \\
\hline$>40$ years & 41815 & 305 & 7.29 & $6.48,8.11$ \\
\hline \multicolumn{5}{|l|}{ Gender } \\
\hline Male & 72369 & 443 & 6.12 & $5.55,6.69$ \\
\hline Female & 124385 & 472 & 3.79 & $3.45,4.14$ \\
\hline \multicolumn{5}{|l|}{ Type of residence } \\
\hline Urban & 95160 & 353 & 3.71 & $3.32,4.10$ \\
\hline Rural & 103594 & 562 & 5.43 & $4.98,5.87$ \\
\hline \multicolumn{5}{|l|}{ Education } \\
\hline No education & 50465 & 411 & 8.14 & $7.36,8.93$ \\
\hline Primary & 29230 & 160 & 5.47 & $4.63,6.32$ \\
\hline Secondary & 94627 & 308 & 3.25 & $2.89,3.62$ \\
\hline Higher & 24389 & 36 & 1.48 & $0.99,1.96$ \\
\hline \multicolumn{5}{|l|}{ Wealth Quintiles } \\
\hline Poorest & 21162 & 119 & 5.62 & $4.62,6.63$ \\
\hline Poorer & 27930 & 192 & 6.87 & $5.91,78.4$ \\
\hline Middle & 38547 & 220 & 5.71 & $4.96,6.46$ \\
\hline Rich & 49482 & 185 & 3.74 & $3.20,4.28$ \\
\hline Richest & 61633 & 119 & 1.93 & $1.58,2.28$ \\
\hline \multicolumn{5}{|l|}{ Region of India } \\
\hline Northern India & 31584 & 89 & 2.82 & $2.23,3.40$ \\
\hline North-eastern India & 34776 & 233 & 6.70 & $5.84,7.56$ \\
\hline Central India & 37987 & 199 & 5.24 & $4.51,5.96$ \\
\hline Western India & 27707 & 126 & 4.55 & $3.76,5.34$ \\
\hline Eastern India & 24606 & 146 & 5.93 & $4.97,6.89$ \\
\hline South India & 42094 & 122 & 2.89 & $2.38,3.41$ \\
\hline
\end{tabular}

*all the comparison were statistically significant $p<0.01$.

$15.6 \%$ of participants said that they "Would keep it a secret from neighbors if a member of their family got tuberculosis".

\section{Determinants of correct knowledge of TB}

Determinants of correct knowledge about TB transmission among participants were assessed by univariate and multivariate analyses (Table 3). By univariate analysis, male gender, being single, living in urban areas, following Hindu or Muslim religion, have higher education and being richer or richest by wealth quintiles were associated with 'correct knowledge about TB transmission'. In addition, reading newspaper every day, watching television everyday and knowing that TB can be cured 
Table 2 Percentage of adult men and women in India responding as 'yes' to questions about tuberculosis transmission

\begin{tabular}{|c|c|c|c|c|}
\hline & & $\begin{array}{l}\text { Men } \\
(\mathrm{N}=68,391)\end{array}$ & $\begin{array}{l}\text { Women } \\
(\mathrm{N}=109,032)\end{array}$ & $\begin{array}{l}\text { Overall } \\
(\mathrm{N}=177,423)\end{array}$ \\
\hline \multirow[t]{13}{*}{1} & How does tuberculosis spread from one person to another? & & & \\
\hline & a)Through the air when coughing or sneezing & 56.3 & 55.0 & 55.5 \\
\hline & b)Through food & 28.7 & 34.9 & 32.4 \\
\hline & c)Through sharing utensils & 16.0 & 19.7 & 18.2 \\
\hline & d)Through touching a person with TB & 11.8 & 12.7 & 12.3 \\
\hline & e)Through sexual contact & 5.9 & 5.0 & 5.3 \\
\hline & f)Through mosquito bites & 1.9 & 1.4 & 1.6 \\
\hline & g)Blood/blood transfusions & 1.1 & 0.7 & 0.9 \\
\hline & h)Through smoking bidis/cigarette/tobacco & 1.1 & 0.5 & 0.7 \\
\hline & i)Through sharing clothes/bed sheets/towel & 0.6 & 0.6 & 0.6 \\
\hline & j)Through spit/sputum/stepping on spit & 0.4 & 0.7 & 0.5 \\
\hline & k)Others & 1.7 & 1.7 & 1.7 \\
\hline & I)Don't know & 23.6 & 28.7 & 26.8 \\
\hline 2 & Can tuberculosis be cured? & 86.5 & 81.5 & 83.5 \\
\hline 3 & $\begin{array}{l}\text { If a member of your family got tuberculosis, would you want it to remain a secret from the } \\
\text { neighbors or not? }\end{array}$ & 15.8 & 15.4 & 15.6 \\
\hline
\end{tabular}

were also associated with correct knowledge. After adjustment for interactions among the explanatory variables being male (aOR 1.17, 95\% CIs 1.14, 1.21), being a Hindu (aOR 1.20 95\% CIs 1.14, 1.26) or Muslim (aOR 1.26, 95\% CIs 1.18, 1.34) and 'TB can be cured' (aOR 1.47 , 95\% CIs 1.41, 1.53) were associated with correct knowledge while education, and wealth quintiles though remained significant, the effect size was very small. Frequency of reading news paper/magazines and watching television were not significant; frequency of listening to radio (aOR 1.08, 95\% CIs 1.04, 1.13) was associated with correct knowledge. Age of the respondent was not associated with correct knowledge by both univariate and multivariate analysis. Participants from Eastern, North-Eastern and Central India were less likely to have correct knowledge about TB transmission while those from Western India were more likely to have correct knowledge about TB transmission (Table 3).

\section{Discussion}

Our analyses revealed that the majority of the participants had heard about TB, though their knowledge about TB transmission was low. It also provided national level prevalence estimates for $\mathrm{TB}$, which is comparable to routine programmatic data. The highlights of our analyses were that nearly half the population knew that TB transmission occurs through air when coughing or sneezing but only a quarter knew about correct mode of TB transmission i.e. without having any misconceptions about it. Encouragingly, the majority of participants knew that TB can be cured and this was associated with having correct knowledge about TB transmission. Among the traditional mass media, only listening to the radio was associated with correct knowledge about TB transmission. From our results, we may interpret that widespread publicity about DOTS may have improved the general awareness about $\mathrm{TB}$, and specifically about the cure for TB. Our results may be useful for managers and policy makers of RNTCP and emphasized the need for evaluation of the IEC activities undertaken by RNTCP.

The strength of our analyses was the calculation of national level prevalence estimates for self-reported TB, and knowledge about transmission of TB from a large representative sample of adult men and women. Our report also includes misconceptions and the stigma about TB which are scarce in the literature. Despite these strengths, we had some limitations and our results should be interpreted with caution. The DHS questionnaire inquired mainly about the modes of transmission but not about TB symptoms and treatment availability. Respondents were not asked about the sources of information about TB. Estimates of self-reported TB in rural areas may have been flawed due to lack of awareness about TB symptoms, low education and the stigma attached with the disclosure of TB. DHS interviewers were well trained to extract such information. However, there may have been an overestimation of self-reported TB and DHS did not have any means to verify self-reported TB by laboratory tests. Assessing the determinants of correct knowledge about TB transmission using a cross-sectional data lacks temporality to interpret a cause-effect relationship.

The prevalence of self-reported TB in our analysis was more than the estimated $\mathrm{TB}$ prevalence reported by WHO and from the annual reports of the Ministry of 
Table 3 Determinants of correct knowledge about Tuberculosis transmission among adult men (aged 15-59 years) and women (aged 15-49 years) by univariate and multivariable analyses

\begin{tabular}{|c|c|c|c|c|c|}
\hline & $\begin{array}{l}\text { Unadjusted odds ratio } \\
(95 \% \mathrm{Cls})\end{array}$ & $\begin{array}{l}\text { Adjusted odds ratio } \\
(95 \% \mathrm{Cls})\end{array}$ & \multicolumn{3}{|c|}{ Reads newspapers/magazines } \\
\hline \multicolumn{3}{|l|}{ Age } & Not at all & 1 & 1 \\
\hline$>40$ years & 1 & 1 & $\begin{array}{l}\text { Once or less in a } \\
\text { week }\end{array}$ & $1.27(1.31)$ & $1.05(1.003,1.09)$ \\
\hline $26-40$ years & $1.02(0.98,1.06)$ & $0.99(0.96,1.03)$ & Everyday & $1.55(1.50,1.61)$ & $1.05(0.99,1.11)$ \\
\hline$\leq 25$ years & $1.01(0.97,1.05)$ & $0.98(0.93,1.03)$ & \multicolumn{3}{|l|}{ Listens to the radio } \\
\hline \multicolumn{3}{|l|}{ Gender } & Not at all & 1 & 1 \\
\hline Female & 1 & 1 & \multirow{2}{*}{$\begin{array}{l}\text { Once or less in a } \\
\text { week }\end{array}$} & \multirow[t]{2}{*}{$0.94(0.91,0.98)$} & \multirow[t]{2}{*}{$1.043(1.01,1.08)$} \\
\hline Male & $1.23(1.20,1.27)$ & $1.17(1.14,1.21)$ & & & \\
\hline \multicolumn{3}{|l|}{ Current marital status } & Everyday & $1.03(0.99,1.06)$ & $1.084(1.04,1.13)$ \\
\hline \multirow{2}{*}{$\begin{array}{l}\text { Divorced/separated/ } \\
\text { widowed }\end{array}$} & \multirow[t]{2}{*}{1} & 1 & \multicolumn{3}{|l|}{ Can TB be cured? } \\
\hline & & & No/don't know & 1 & 1 \\
\hline Single & $0.84(0.77,0.91)$ & $0.94(0.86,1.04)$ & Yes & $1.44(1.39,1.50)$ & $1.47(1.41,1.53)$ \\
\hline
\end{tabular}

Table 3 Determinants of correct knowledge about Tuberculosis transmission among adult men (aged 15-59 years) and women (aged 15-49 years) by univariate and multivariable analyses (Continued)

Reads newspapers/magazines

Not at al

Once or less in a

$1.47(1.41,1.53)$

Religion

Others

Muslim

1

Hindu

$1.52(1.43,1.61)$

1

$1.26(1.18,1.34)$

$1.20(1.14,1.26)$

Type of residence

Urban

1

Rural

$0.80(0.78,0.83)$

$0.98(0.95,1.02)$

Educational attainment

\begin{tabular}{|c|c|c|}
\hline No education & 1 & 1 \\
\hline Primary & $1.17(1.13,1.23)$ & $1.07(1.02,1.12)$ \\
\hline Secondary & $1.42(1.34,1.50)$ & $1.10(1.03,1.18)$ \\
\hline Higher & $1.62(1.55,1.71)$ & $1.08(1.004,1.16)$ \\
\hline \multicolumn{3}{|l|}{ Wealth quintiles } \\
\hline Poorest & 1 & 1 \\
\hline Poorer & $1.11(1.07,1.53)$ & $1.02(0.98,1.06)$ \\
\hline Middle & $1.29(1.24,1.35)$ & $1.09(1.03,1.14)$ \\
\hline Richer & $1.51(1.44,1.58)$ & $1.12(1.05,1.19)$ \\
\hline Richest & $1.59(1.51,1.67)$ & $1.12(0.99,1.14)$ \\
\hline \multicolumn{3}{|l|}{ Region of India } \\
\hline Northern India & 1 & 1 \\
\hline North-eastern India & $0.58(0.55,0.61)$ & $0.58(0.54,0.61)$ \\
\hline Central India & $0.79(0.75,0.85)$ & $0.85(0.80,0.90)$ \\
\hline Western India & $1.27(1.19,1.35)$ & $1.21(1.14,1.28)$ \\
\hline Eastern India & $0.52(0.49,0.55)$ & $0.54(0.51,0.58)$ \\
\hline South India & $1.02(0.96,1.08)$ & $1.01(0.95,1.08)$ \\
\hline \multicolumn{3}{|l|}{ Watches television } \\
\hline Not at all & 1 & 1 \\
\hline $\begin{array}{l}\text { Once or less in a } \\
\text { week }\end{array}$ & $1.30(1.26,1.35)$ & $0.99(0.96,1.03)$ \\
\hline Everyday & $1.45(1.39,1.50)$ & $0.977(0.93,1.03)$ \\
\hline
\end{tabular}

Health (MOH), Government of India (GOI) [5,9]. It is not clear from our analysis, if there was under-reporting because the questions asked during the survey were not specific to pulmonary and extra-pulmonary TB. Moreover, extra-pulmonary $\mathrm{TB}$ which is less known in the general population may not have been reported by the survey respondents. Despite the skepticism regarding self-reports about health and disease status in surveys, we believe that self-reported TB in DHS is reliable $[26,27]$. The data are comparable to existing reports on TB burden in India [5,9]. The socio-economic patterning of TB was in accordance with the previous reports [28-30]. TB experts have recommended that socioeconomic data should be measured during TB surveys [31]. However we did not perform further analysis on determinants of $\mathrm{TB}$ using other explanatory variables since in this survey TB was a self-report. Higher prevalence of TB in rural areas and in North-Eastern and Eastern states is also in accordance with annual reports of $\mathrm{MOH}, \mathrm{GOI}[9]$.

Several studies from different countries about awareness, perceptions, attitudes, and treatment seeking behaviors for TB have reported that awareness about TB in the general population is poor and treatment seeking behavior is not appropriate [15,21,23,32-36]. However, most of these except our study and a report from Bangladesh [24] were small scale surveys and lacked the implications on policy making at the national level. A good knowledge about TB symptoms in the general population may help to improve health-care seeking behavior of patients [10]. Knowledge about transmission of TB is also important to protect oneself from infection with TB by following cough etiquette and respiratory hygiene which are critical in preventing TB transmission [37]. Our results suggest that 
prevention of TB transmission in the general population of India is less likely since people did not know the correcmode of TB transmission and people had misconceptions about it. In the neighboring country of Bangladesh, the proportion of women knowing correctly about TB transmission was much lower [24]. Correct knowledge about TB transmission was associated with education and income, but among mass media, only the frequency of listening to radio was associated with correct knowledge which was similar to the results reported from Bangladesh [24]. Inadequate knowledge about $\mathrm{TB}$ transmission in India may be due to lack of IEC messages about TB transmission before and during the time of DHS survey i.e. 2005-06. The IEC messages which focused on symptoms, curability and availability of treatment (DOTS) were disseminated by the RNTCP, which implements TB control activities in India. The IEC activities were meant to achieve the targets in terms of case detection rate and cure rates set by RNTCP. In pursuit of these targets, RNTCP program planners may have missed the inclusion of messages about TB transmission. However, recently, the pamphlets about facts of TB contain the message "TB is spread through coughing or sneezing of a TB patient." While case detection and cure of TB is secondary prevention, prevention of TB transmission before infectious cases are diagnosed and treated is primary prevention. We emphasize that primary prevention cannot be overlooked considering the reports about diagnostic delays in high burden countries $[11,12]$.

\section{Policy implications}

Currently, knowledge about symptoms and transmission of TB, stigma about TB, and health seeking behavior for $\mathrm{TB}$ are not measured in program evaluation. Inclusion of such indicators into periodic program evaluation may serve as a guide to improve the program's performance. Two studies about the evaluation of IEC activities of RNTCP done in New Delhi have reported about issues other than TB transmission and have called for an improvement in IEC strategies [16,18]. Lack of association of correct knowledge about TB transmission with traditional mass media such as television, newspapers and magazines shows the need for using other means to disseminate IEC messages about TB $[16,18]$. This may be due to lower levels of literacy prevailing in India. People belonging to the poorest wealth quintiles were more likely to have TB while the frequency of listening to radio was associated with knowledge about TB transmission. Since radio is more affordable to the poorest people, radio may be used to intensify IEC activities. TB control program planners should also consider primary prevention in addition to early diagnosis and treatment. The regional differences in TB prevalence and knowledge of TB transmission should be considered in program planning. Areas with high TB prevalence and lower knowledge may need advocacy, communication and social mobilization as recommended by STOP-TB initiative $[13,14,19]$. Nation-wide surveys like DHS provide a good opportunity to study further about TB knowledge and health behavior towards TB. Future DHS surveys may include questions about the knowledge of TB symptoms and treatment seeking behavior among people having cough lasting three weeks or more. As DHS surveys are not done frequently, RNTCP could consider inclusion of TB knowledge, and health-care seeking behavior for $\mathrm{TB}$ in their program evaluation to assess the impact of IEC activities on the diagnosis of TB [17].

\section{Conclusion}

Knowledge about TB transmission in the general population of India is very poor and misconceptions about TB transmission prevailed. Among traditional mass media, only the frequency of listening to radio was associated with knowledge about TB transmission. TB control program should include more information about TB transmission in its IEC messages and alternative mass media such as radio could be considered when delivering messages about $\mathrm{TB}$.

\section{Competing interests}

The authors declare that they have no competing interests.

\section{Authors' contributions}

CTS: Conceptualized the research, conducted the data analysis, interpreted the results and wrote the first draft of the manuscript for publication; HNHK Helped conceptualizing the research, planned data analysis and revised earlier drafts of the manuscript; JTA: Assisted in drafting the manuscript, commented draft versions of the manuscript for publication. All the authors read and approved the final version of the manuscript to be submitted for publication in a scientific journal.

\section{Acknowledgements}

We thank ORC Macro International for providing us with the data necessary to carry out the analysis and to prepare this manuscript. We also wish to thank Associate Professor Dr. Robert Chen, Faculty of Medicine and Health Sciences, Universiti Tunku Abdul Rahman for proof reading and language editing our Manuscript.

\section{Author details}

'Department of Clinical Sciences, Faculty of Medicine and Health Sciences, Universiti Tunku Abdul Rahman, Sungai Long, Malaysia. ${ }^{2}$ Department of Community Medicine, Kasturba Medical College, Mangalore, India.

${ }^{3}$ Department of Community Medicine, International Medical University, Kuala Lumpur, Malaysia.

Received: 1 February 2012 Accepted: 14 January 2013

Published: 17 January 2013

\section{References}

1. Sudre P, Ten DG, Kochi A: Tuberculosis: a global overview of the situation today. Bull World Health Organ 1992, 70:149-159.

2. WHO global tuberculosis control report 2010. Summary. Cent Eur J Public Health 2010, 18:237.

3. Lopez AD, Mathers CD, Ezzati M, Murray CJL, Jamison DT: Global burden of disease and risk factors. New York, NY, USA: Oxford University Press and World Bank 2006; 2006

4. Chakraborty AK: Epidemiology of tuberculosis: current status in India. Indian J Med Res 2004, 120:248-276. 
5. World Health Organisation: Global Tuberculosis Control WHO REPORT 2009 Geneva: World Health Organisation; 2009.

6. World Health Organization. WHO Report 2003: Global Tuberculosis Control Surveillance, planning, financing. In WHO/CDS/TB/2003.316. Geneva: World Health Organization; 2003.

7. Central TB division. Directorate General of Health Services MoHaFW: Revised National Tuberculosis Control Programme. Managing the National Tuberculosis Control Programme in your area: a training course. New Delhi: Ministry of Health and Family Welfare; 2005.

8. Nair SS: Ethical aspects of the Revised National Tuberculosis Control Programme. Indian J Med Ethics 2011, 8:102-106.

9. Chauhan LS: Status report on RNTCP. Indian J Tuberc 2011, 58:38-40.

10. Jaramillo E: Encompassing treatment with prevention: the path for a lasting control of tuberculosis. Soc Sci Med 1999, 49:393-404.

11. Sreeramareddy CT, Panduru KV, Menten J, Van den Ende J: Time delays in diagnosis of pulmonary tuberculosis: a systematic review of literature. BMC Infect Dis 2009, 9:91.

12. Storla DG, Yimer S, Bjune GA: A systematic review of delay in the diagnosis and treatment of tuberculosis. BMC Public Health 2008, 8:15.

13. Raviglione MC: The global plan to stop TB, 2006-2015. Int J Tuberc Lung Dis 2006, 10:238-239.

14. Raviglione MC, Uplekar MW: WHO's new stop TB strategy. Lancet 2006, 367:952-955.

15. Suganthi P, Chadha VK, Ahmed J, Umadevi G, Kumar P, Srivastava R, et al: Health seeking and knowledge about tuberculosis among persons with pulmonary symptoms and tuberculosis cases in Bangalore slums. Int J Tuberc Lung Dis 2008, 12:1268-1273.

16. Sharma N, Taneja DK, Pagare D, Saha R, Vashist RP, Ingle GK: The impact of an IEC campaign on tuberculosis awareness and health seeking behaviour in Delhi, India. Int J Tuberc Lung Dis 2005, 9:1259-1265.

17. Jaramillo E: The impact of media-based health education on tuberculosis diagnosis in Cali, Colombia. Health Policy Plan 2001, 16:68-73.

18. Sharma N, Nath A, Davender KT, Gopal Kl: A qualitative evaluation of the information, education, and communication component of the tuberculosis control program in Delhi, India. Asia Pac J Public Health 2009, 21:321-332.

19. Kamineni W, Turk T, Wilson N, Satyanarayana S, Chauhan LS: A rapid assessment and response approach to review and enhance advocacy, communication and social mobilisation for tuberculosis control in Odisha state, India. BMC Public Health 2011, 11:463.

20. Datta K, Bhatnagar T, Murhekar M: Private practitioners' knowledge attitude and practices about tuberculosis, Hooghly district, India. Indian J Tuberc 2010, 57:199-206.

21. Karim F, Johansson E, Diwan VK, Kulane A: Community perceptions of tuberculosis: a qualitative exploration from a gender perspective. Public Health 2011, 125:84-89.

22. Rajpal S, Mittal A, Dhingra VK, Malhotra R, Gupta R, Malhotra C, et al: Knowledge, attitude and practices regarding tuberculosis and DOTS among interns in Delhi, India. J Coll Physicians Surg Pak 2007, 17:457-461.

23. Sharma N, Malhotra R, Taneja DK, Saha R, Ingle GK: Awareness and perception about tuberculosis in the general population of Delhi. Asia Pac J Public Health 2007, 19:10-15.

24. Khandoker A, Khan MM, Kramer A, Mori M: Knowledge about tuberculosis transmission among ever-married women in Bangladesh. Int J Tuberc Lung Dis 2011, 15:379-384.

25. International Institute for Population Sciences (IIPS) and Macro International: National family health survey (NFHS-3), 2005-06: India. 1st edition. Mumbai: IIPS; 2007.

26. Sen A: Health: perception versus observation. BMJ 2002, 324:860-861.

27. Subramanian SV, Subramanyam MA, Selvaraj S, Kawachi I: Are self-reports of health and morbidities in developing countries misleading? Evidence from India. Soc Sci Med 2009, 68:260-265.

28. Kaulagekar A, Radkar A: Social status makes a difference: tuberculosis scenario during National Family Health Survey-2. Indian J Tuberc 2007, 54:17-23.

29. Muniyandi M, Ramachandran R, Gopi PG, Chandrasekaran V, Subramani R, Sadacharam K, et al: The prevalence of tuberculosis in different economic strata: a community survey from South India. Int J Tuberc Lung Dis 2007, 11:1042-1045.

30. Muniyandi M, Ramachandran R: Socioeconomic inequalities of tuberculosis in India. Expert Opin Pharmacother 2008, 9:1623-1628.
31. Van LF, Guilatco RS, Hossain S, Van't Hoog AH, Hoa NB, VAN DER Werf MJ, et al: Measuring socio-economic data in tuberculosis prevalence surveys. Int J Tuberc Lung Dis 2011, 15(Suppl 2):58-63.

32. Kar M, Logaraj M: Awareness, attitude and treatment seeking behaviour regarding tuberculosis in a rural area of Tamil Nadu. Indian J Tuberc 2010, 57:226-229.

33. Rajeswari R, Muniyandi M, Balasubramanian R, Narayanan PR: Perceptions of tuberculosis patients about their physical, mental and social well-being: a field report from south India. Soc Sci Med 2005, 60:1845-1853.

34. Rintiswati N, Mahendradhata Y, Suharna, Susilawati, Purwanta, Subronto Y, et al: Journeys to tuberculosis treatment: a qualitative study of patients, families and communities in Jogjakarta, Indonesia. BMC Public Health 2009, 9:158.

35. Wang $H$, Huang $R$, Zhao $Y$, Liu $X$ : [The study on pulmonary tuberculosis knowledges and its influencing factors among middle school students of Three-Gorges Reservoir in Chongqing]. Wei Sheng Yan Jiu 2009, 38:706-708.

36. Wang J, Fei $Y$, Shen $H, X u$ B: Gender difference in knowledge of tuberculosis and associated health-care seeking behaviors: a crosssectional study in a rural area of China. BMC Public Health 2008, 8:354.

37. Longtin Y, Akakpo C, Rutschmann OT, Pittet D, Sax H: Evaluation of patients' mask use after the implementation of cough etiquette in the emergency department. Infect Control Hosp Epidemiol 2009, 30:904-908.

doi:10.1186/1471-2334-13-16

Cite this article as: Sreeramareddy et al.: Prevalence of self-reported tuberculosis, knowledge about tuberculosis transmission and its determinants among adults in India: results from a nation-wide crosssectional household survey. BMC Infectious Diseases 2013 13:16.

\section{Submit your next manuscript to BioMed Central and take full advantage of:}

- Convenient online submission

- Thorough peer review

- No space constraints or color figure charges

- Immediate publication on acceptance

- Inclusion in PubMed, CAS, Scopus and Google Scholar

- Research which is freely available for redistribution

Submit your manuscript at www.biomedcentral.com/submit
C) BioMed Central 